Royal College of Physicians of london \& Royal College OF PSYCHIATRISTS (1989) Care of Elderly People with Mental Illness: Specialist Services and Medical Training. London: Royal College of Physicians and Royal College of Psychiatrists.

Wartis, J. P. (1988) Geographical variations in the provision of psychiatric services for old people. Age and Ageing, 17, 171-180.

- (1991) To the editor. Health Trends, 23, 44.

-. WATtis, L. \& ARIE, T. H. (1981) Psychogeriatrics: a national survey of a new branch of psychiatry. British Medical Journal, 282, 1529-1533.

- \& ARIE, T. H. (1984) Further developments in psychogeriatrics in Britain. British Medical Journal, 289. 778.
Wind, A. W., Van Staveren, G., Schellevis, F. G., et al (1994) The validity of the judgement of general practitioners on dementia. International Joumal of Geriatric Psychiatry, 9. 543-549.

John Wattis, Medical Director, Leeds Community and Mental Health Services NHS Trust, The Mansion, Meanwood Park Hospital, Tongue Lane, Leeds LS6 4QB; Andrew MacDonald, Consultant Psychiatrist, Wakefield and Pontefract Community Health Trust; and Paul Newton, Clinical Audit Manger, Leeds Community and Mental Health Services NHS Trust, Leeds

\title{
National differences in disulfiram prescribing
}

\author{
Jonathan Chick and Colin Brewer
}

\begin{abstract}
Aims and method To test the impression of wide national differences in the use of deterrent medication in the treatment of alcohol dependence, data showing comparative sales of disulfiram in 13 countries were obtained.

Results Sales in Britain were lowest, and less than a tenth of those in Denmark. Rates bore no relation to alcohol sales or an index of alcohol-related problems in the 13 countries.

Clinical implications British doctors may apply a particularly cautious risk/benefit ratio for disulfiram. The disparity may also reflect the predominantly nonmedical approach to treating alcohol dependence in Britain.
\end{abstract}

Hughes \& Cook (1997) reported that, in a trial of acamprosate, patients who chose to take disulfiram in addition to their trial drug had the lowest relapse rate (Bresson et al, 1998). In a pilot study research showing that naltrexone and acamprosate have clinically significant effects in reducing relapse in alcohol dependency has renewed interest in the pharmacological treatment of alcohol use disorders. When given under supervision, reviewers agree that supervised disulfiram helps reduce relapse in some people with alcohol problems (Heather, 1989, 1993; Brewer 1993; Hughes \& Cook, 1997). There has been no trial comparing its efficacy to acamprosate, but a pilot study has shown that it was twice as effective as naltrexone in reducing alcohol intake in patients with alcohol dependency who use cocaine (Carroll et al, 1993). The following data were obtained to compare the prescribing of disulfiram in various countries including Britain.

\section{The study}

Pharmaceutical sales are not generally disclosed. However, Dumex, the principal manufacturer of disulfiram, was asked to supply details for three consecutive years of tablet sales per 100000 of the adult population in 13 countries where their brand is the sole preparation available (except for the USA, where the figure includes all generic brands). Dumex divided the figures by a coeffcient to disguise actual sales while preserving relativities.

\section{Results}

Comparative sales in the 13 countries are shown in Table 1. Interpretation is complicated by the availability of several tablet sizes of disulfiram $(200 / 400 \mathrm{mg}$ or $250 / 500 \mathrm{mg})$ in most countries. Only $200 \mathrm{mg}$ tablets are available in Britain. Comparing the number of tablets sold in each 
Table 1. Relative disulfiram sales by country, per 100000 adult population (coefficient - adjusted: see text)

\begin{tabular}{lrrr}
\hline & 1993 & 1994 & 1995 \\
\hline Denmark & 1129 & 1123 & 1121 \\
Sweden & 472 & 463 & 545 \\
Switzerland & 343 & 328 & 448 \\
Finland & 315 & 402 & 322 \\
Norway & 240 & 214 & 215 \\
Czechoslovakia & N/A & 61 & 156 \\
Eire & N/A & N/A & 155 \\
Italy & 99 & 99 & 132 \\
Austria & 31 & 65 & 116 \\
Holland & 115 & 122 & 114 \\
USA & 93 & 93 & 92 \\
New Zealand & 117 & 59 & 73 \\
UK & 51 & N/A & 53 \\
\hline
\end{tabular}

N/A not available

country, regardless of tablet size. Britain has the lowest rate of the 13 countries.

\section{Discussion}

Possible explanations for the relatively low use of disulfiram in the UK are as follows.

\section{Lower prevalence of alcohol misuse}

The order in Table 1 does not correspond either to rates of alcohol dependency reflected in alcohol cirrhosis mortality, or to the per capita consumption of alcohol, both of which would put Austria and Czechoslovakia at the top and Norway and Sweden at the bottom (World Drink Trends, 1992). Thus, variation in prevalence is at most only a partial explanation.

\section{Misunderstanding regarding efficacy}

Some well known controlled studies of the efficacy of disulfiram such as that of Veterans Administration study (Fuller et al, 1986) found no advantage to disulfiram in the all-patient outcome analysis. It is only when disulfiram administration has been supervised that randomised controlled studies have shown an advantage of disulfiram over the control condition (see review by Hughes \& Cook, 1997). There was no supervision in the Veterans Administration study. Nevertheless, that study found that among patients who complied, in the sense of coming to all their appointments, and might therefore also have complied in taking their medication, the accumulated drinking over the one year of the study was significantly less in the disulfiram group.

\section{Importance of supervision}

The importance of supervision seems to have been missed in UK teaching, such as it is, about disulfiram. Until recently psychiatry textbooks gave few details of disulfiram treatment and lacked up-to-date references. Supervision is not mentioned in successive editions of the British National Formulary (1997) nor in the International Handbook of Addictive Behaviour (Glass, 1991). The Treatment of Drinking Problems (Edwards et al, 1997) has only now, in its third edition, expanded its section on disulfiram treatment to discuss supervision (the second edition (Edwards, 1987) stated that: "in many cases . . . disulfiram should at least be offered"). Until recently, little advice has been given on how to set up a supervision arrangement (or 'partnership arrangement' as it is best called). This may be with the spouse, a community agency, an employer, in primary care or at the clinic. There is a method to doing it successfully (Chick, 1996).

Improving compliance is important in therapies to prevent relapse in addiction. Few patients do not, at times, wish to resume their former pleasure. When naltrexone has been examined as an aid to preventing relapse in alcohol dependency, three separate sets of data from randomised controlled trials have shown compliance in taking the drug to be crucial (O'Brien et al, 1996; Volpicelli et al, 1997; further details available from the authors upon request). Naltrexone, if given under rigorous supervision in the treatment of opiate addiction, is associated with a clinically very significant reduction in relapse (Chan et al, 1996).

\section{Attitudes among members of \\ Alcoholics Anonymous}

The similarity between the British. New Zealand and USA figures suggests that certain AngloSaxon influences may be important. These countries have, per capita, more numerous Alcoholics Anonymous (AA) groups than the other 13 countries in Table 1. Some AA groups oppose disulfiram treatment, and it is possible that this has influenced medical practice and patients' attitudes too. This attitude is not strictly speaking that of $A A$ : the leading $A A$ publication (Alcoholics Anonymous, 1975) which mentions disulfiram treatment, would not oppose it, except in the case where it replaced AA attendance, but instead equates taking disulfiram with other personal decisions such as entering psychotherapy or changing jobs - that is, it is for the individual to decide if an aid in attaining abstinence is appropriate.

\section{The psychological approach}

The low rate of use of disulfiram in the UK and perhaps in the other Anglo-Saxon countries in 
Table 1 may reflect what Caplehorn (1995) describes as an excessively psychological approach in Britain to the theory and practice of addiction treatment. If so, this is ironic since several of the most persuasive controlled studies of supervised disulfiram have been carried out by psychologists.

For the past 20 years a large proportion of people with alcohol problems seeking help in the UK have been treated by voluntary and lay agencies originally known as Councils on Alcoholism and for many service users, controlled drinking was an agreed goal. Indeed, the Councils have been a backbone of the UK treatment system. The training of counsellors was greatly influenced by the writings of British social scientists (e.g. Heather \& Robertson, 1981; Shaw, 1985; Davies, 1992) who eschewed the concept of dependence, and with it the 'medical approach'. This too may have reduced the numbers of individuals with alcohol dependency who knew of disulfiram or who were advised to consider it.

There appears to be a very low use in the UK compared with some other countries of the supervised administration of the opiate antagonist, naltrexone (Brewer, 1996), and these explanations may also apply to that phenomenon.

\section{Fear of adverse drug events}

It is possible that British doctors are particularly sensitised to the dangers of disulfiram. Very few deaths have occurred in the UK (Henry, personal communication, 1997), but fatalities are reported in the international literature.

Aversive reaction to ethanol The aversive reaction to ethanol at higher doses of disulfiram can be fatal. Reviewing 13 reports of fatalities Amador \& Gazdar (1967) found that the dosage of disulfiram was $1 \mathrm{~g}$ or more daily, although their own case had been taking $500 \mathrm{mg}$ daily. The patient died after drinking one US pint $(500 \mathrm{ml})$ of whisky, but had drunk two pints of whisky the previous day. Some of the reported deaths were clearly suicidal. Most reports date from the early days of disulfiram treatment when doses as high as $\mathbf{2} \mathrm{g}$ daily were commonly used, as in the case described by Becker \& Sugarman (1952). A death on such a dose during an alcohol reaction has also been reported due to intracranial haemorrhage (Guarnachelli et al, 1972).

However, the recommended maintenance dose in Britain is $200 \mathrm{mg} /$ day, which in practice usually has a deterrent effect, because many people do not risk testing the effect of alcohol, but is actually insufficient to produce more than a mildly unpleasant reaction with alcohol in perhaps one-third of patients (Brewer, 1984. 1993). This has presumably contributed to the extreme rarity of serious alcohol disulfiram reactions reported in UK.

Idiosyncratic hepatitis Death from idiosyncratic hepatitis has occurred. The mortality is $1: 25000$ patient years (Goyer \& Major, 1979; Poulsen et al. 1992). It is disproportionately associated with the other indication for disulfiram, chelation treatment for nickel toxicity and severe nickel dermatitis (Sunderman, 1958; Kaaber et al, 1987; Forns et al, 1994; Brewer. 1996). Indeed some commentators regard the risk as so rare, and indiosyncratic, that regular liver toxicity tests need not be carried out. assuming the patient is being regularly seen, as should be the case for all patients on drug therapy (Dilts \& Dilts, 1996).

There is probably excessive caution in the UK with regard to using disulfiram in patients with abnormal liver function. There is no evidence that pre-existing alcoholic liver disease increases the risk. Black \& Richardson (1986) concluded that liver disorder, if alcohol related, should not deter the clinician from using this drug in a patient in whom there is a high risk of harm from return to drinking. Liver disorder is not listed in the data sheet as a contraindication to disulfiram. In randomised controlled studies comparing disulfiram with placebo, the incidence of abnormal liver function tests is not greater in the disulfiram group than the placebo group (Iber et al. 1987; Chick et al, 1992). In fact, in the UK study (Chick et al, 1992) there was a significantly greater improvement in serum gamma glutamyl transferase activity in the disulfiram group than the placebo group.

The rare deaths from drinking while taking disulfiram need to be set in the context of high mortality rates in many follow-up studies of patients with alcohol dependency; for example $14.5 \%$ in four years -2.5 times the expected rate - in the Rand study (Polich et al, 1981).

Non-fatal adverse effects There are occasional instances of dose-related peripheral neuropathy, fully reversible if detected early. Psychosis has been reported, but must be rare (Branchey et al, 1987). Minor unwanted effects occur in $10 \%$ of patients, tiredness and headache being the most common. While this may disappear in some patients, either with or without dose reduction, other patients then have the choice whether or not to continue.

Drug interactions The data sheet lists a number of possible interactions, which are relative rather than absolute contraindications to concomitant use of disulfiram. Comparisons with the rates of adverse effects in other drugs place disulfiram as a drug of 'intermediate risk', with adverse effects being reported at a rate of between 1 in 20 and 1 
in 2000 reactions per treatment per year (Poulsen et al, 1992). There is no evidence to suggest that British doctors have been particularly cautious, but it is possible that a sensitivity by them has led to lower prescribing rates.

\section{Reluctance to prescribe in primary care}

Disulfiram is routinely used by general practitioners (GPs) in Denmark and other countries. In Britain, its promotion to GPs by the manufacturer was prohibited for several years by the Department of Health despite Department of Health (1989) pamphlets advising GPs to consider it in cases unresponsive to simpler approaches. However, we have no data to indicate whether this has contributed to the comparatively low rate of disulfiram use in the UK.

\section{Comment}

There is a low rate of use of disulfiram in UK compared with a number of other countries. Misunderstanding about efficacious mode of use, the British tradition of a psychological emphasis in the treatment of addictions, and perhaps a particularly cautious view of the adverse effects of the drug have probably contributed.

\section{Acknowledgements}

Both authors attended a scientific meeting at which expenses were partly met by pharmaceutical companies related to the Dumex company.

\section{References}

ALCоноLics ANonmous (1975) Living Sober. Pp. 60. London: Jupiter.

AMADOR, E. \& GAZDAR, A. (1967) Sudden death during disulfiram alcohol reaction. Quarterly Joumal of Studies on Alcohol, 28, 649-654.

Becker, M. \& Sugarman, G. (1952) Death following 'test drink' of alcohol in patients receiving Antabuse. Journal of the American Medical Association. 149, 568-571.

Besson, J., AEby, F., Kasas, A., et al (1998) Combined efficacy of acamprosate and disulfiram in the treatment of alcoholism: a controlled study. Alcohol and Alcoholism. 22. 573-579.

BLACK, J. \& RICHARDSON, J. (1985) Disulfiram hepatotoxdcity: case report. Journal of Clinical Psychiatry, 46, 67-68.

BRANCHEY, L., DAVIS, W., LEE, K. K., et al (1987) Psychiatric complications of disulfiram treatment. American Journal of Psychiatry, 144, 1310-1312.

BREWER, C. (1984) How effective is the standard dose of disulfiram? A review of the alcohol-disulfiram reaction in practice. British Journal of Psychiatry, 144, 200-202.

- (1993) Invited review: recent developments in disulfiram treatment. Alcohol \& Alcoholism, 28, 383-395.

- (1996) On the specific effectiveness, and under-valuing. of pharmacological treatments for addiction: a comparison of methadone, naltrexone and disulfiram with psychosocial interventions. Addiction Research, 3 297-313.
BRTTSH NATIONAL FORMULARY (1997) British National Formulary. London: British Medical Association and Royal Pharmaceutical Society of Great Britain.

CAPLEHORN. J. R. M. (1995) Methadone maintenance treatment: Britain has been over-committed to psychological theories of drug dependence. British Medical Journal, 310, 465.

CARROLL, K., ZIEDONIS, D., O'MALLEY, S., et al (1993) Pharmacological interventions for alcohol- and cocaine-abusing individuals: A pilot study of disulfiram vs. naltrexone. American Joumal on Addictions, 2, 77-79.

Chan, K. Y. (1996) The Singapore naltrexone communitybased project for heroin addicts compared with a drugfree community-based programme: the first cohort. Journal of Clinical Forensic Medicine, 3. 87-92.

CHICK, J. (1996) Medication in the treatment of alcohol dependence. Advances in Psychiatric Treatment. 2. 249-257.

-. GOUGH, K., FALKowsk, W., et al (1992) Disulfiram treatment of alcoholism. British Joumal of Psychiatry. 161. 84-89.

DAVIES. J. B. (1992) The Myth of Addiction - An Application of the Psychological Theory of Attribution of Ilicit Drug Use. Char: Harwood Academic Press.

Department of Health Working Party on Alcohol Misuse (1989) Drinking Problems-A Challenge for Every Doctor. London: Department of Health.

DiLTS. S. \& DiLTS. S. (1996) Assessing liver function before initiating disulfiram therapy. American Journal of Psychiatry. 153, 1504-1505.

EDWARDS, G. (1987) The Treatment of Drinking Problems: A Guide for the Helping Professions (2nd edn). Oxford: Blackwell.

-. Marshall, J., COOK. C. C. (1997) The Treatment of Drinking Problems. (3rd edn). London: Cambridge University Press.

Forns, X. Caballeria, J., Bruguera, M., et al (1994) Disulfiram-induced hepatits. Report of four cases and review of the literature. Joumal of Hepatology. 21. 853-857.

FULLER, R. K. BRANCHEY, L., BRIGHTWELL. D. R., et al (1986) Disulfiram treatment of alcoholism. Journal of the American Medical Society. 258, 1449-1455.

GLASS, I. (ed.) (1991) International Handbook on Addictive Behaviour. London: Routledge.

GOYER, P. \& MAJOR, L. (1979) Hepatotoxdcity in disulfiram-treated patients. Journal of Studies on Alcohol, 2, 133-137.

GUARNASCHELU. J., ZAPANTA, E. \& PITTS, G. (1972) Intracranial haemorrhage associated with the disulfiram-alcohol reaction. Bulletin of the Los Angeles Neurological Society. 37, 19-23.

HEATHER, N. (1989) Disulfiram treatment in alcoholism: deserves a second chance? British Medical Journal. 299. 471-472.

- (1993) Disulfiram treatment for alcohol problems: is it effective, and if so. why? In Treatment Options in Addiction: Medical Management of Alcohol and Opiate Abuse (ed. C. Brewer), pp. 1-18. London: Gaskell.

- \& Robertson. I. (1981) Controlled Drinking. London: Methuen.

Hughes, J. C. \& СоOK. C. (1997) The efficacy of disulfiram - a review of outcome studies. Addiction. 92, 381-396.

IBER, F. L., LEE, K., LACOURSIERE, R., et al (1987) Liver toxicity encountered in the Veterans Administration trial of disulfiram in alcoholics. Alcoholism: Clinical and Experimental Research, 11, 301-304.

KAABER, K., MENNE. T., VEIEn, N.. et al (1987) Some adverse effects of disulfiram in the treatment of nickel-allergic patients. Dermatosen Beruf Umuelt, 38, 211. 
O'Brien, C. P., Volpicell, L. A. \& Volpiceld, J. R. (1996) Naltrexone in the treatment of alcoholism: a clinical review. Alcohol, 13, 35-39.

POLCH, J. M., ARMOR, D. \& BRAIKER, H. (1981) The Course of Alcoholism Four Years After Treatment. New York: John Wiley and Sons.

POUlsen, E. H., Loft, S., ANDERSEN, J. R., et al (1992) Disulfiram therapy adverse drug reaction and interactions. Acta Psychiatrica Scandinavida, 86, 59-66.

Shaw, S. (1985) The disease concept of dependence. In The Misuse of Alcohol: Crucial Issues on Dependence. Treatment and Prevention (eds N. Heather, I. Robertson \& P. Davies). London: Croom Helm.

SUNDERMAN, F. W. (1958) Dithiocarb: a new therapeutic agent for persons exposed to nickel carbonyl. American Journal of Medical Science, 236, 26-30.
VOlPICELU, J. R., RHINES, K. C., RHINES, J. S., et al (1997) Naltrexone and alcohol dependence. Archives of General Psychiatry, 64, 1737-1742.

WORID DRINK TRENDS (1992) World Drink Thends, International Beverage Alcohol Consumption and Production Trends. Henley-on-Thames: Produktschap voor Gedistillerde Dranken and NTC Publications.

* Jonathan Chick, Senior Lecturer in Psychiatry, University of Edinburgh, Royal Edinburgh Hospital, Edinburgh EHIO 5HF; and Colin Brewer, Medical Director, The Stapleford Centre, London SWI 9PN

*Correspondence

\title{
Use of high-dose depot neuroleptics
}

\author{
N. Purandare, L. Aitken, P. Joshi and C. S. Thomas
}

Aims and methods To identify and reduce the number of patients recelving depot neuroleptics above the British National Formulary maximum. The medical records were scrutinised and individual consultants were informed of the results.

Results For the team involved in this audit, there was a significant reduction in the prescription of high-dose depot medication, but this did not generalise to other teams.

Clinical implications Different teams should repeat the audit and a new depot card has been developed.

The use of high doses of neuroleptics is being increasingly questioned both on the grounds of safety and efficacy (King, 1994). The occasional association of sudden death in psychiatric patients and high-dose antipsychotic treatment has prompted comment and a consensus statement (Hirsch \& Barnes, 1994; Thompson, 1994). Side-effects such as sedation, respiratory depression, cardiotoxicity, seizures, tardive dyskinesias, extrapyradimal side-effects, neuroleptic malignant syndrome, sudden death and paradoxical deterioration of behaviour are also more likely at higher doses (Mackay, 1994).

Although controlled studies comparing standard doses with high doses of neuroleptics in treatment-resistant schizophrenia fail to show superior effectiveness of the 'megadose' regime (Kane, 1994), some patients do seem to respond to high doses of neuroleptics (Cookson. 1987) and a cautious trial of treatment may be justified. In such cases it would seem reasonable to expect that alternative management options have been considered (Tarrier, 1992), the patient's response to treatment and possible side-effects are carefully recorded and that the prescriber is a senior doctor. This becomes particularly important when medico-legal implications are considered.

In South Manchester Health District, there was no established system for identifying patients receiving doses of depot neuroleptics which exceed the maximum recommended by the British National Formulary (BNF).

\section{Aims}

(a) Identify the patients receiving depot neuroleptics at doses exceeding BNF maximum.

(b) Identify the reasons for using a high dose and whether any side-effects were recorded.

(c) Increase the awareness among consultant teams about these patients.

(d) Examine any changes in the prescribing habits of the consultant teams after they were made aware of such patients. 